\title{
The possible antioxidant capabilities of formononetin in guarding against streptozotocin-induced diabetic nephropathy in rats
}

\author{
Pankaj G. Jain ${ }^{1 *}$, Priti G. Nayse ${ }^{1}$, Dipali J. Patil ${ }^{1}$, Sachin D. Shinde ${ }^{2}$ and Sanjay J. Surana ${ }^{1}$
}

\begin{abstract}
Background: Oxidative stress has been considered as a contributory aspect for major complications of diabetes mellitus consisting of diabetic nephropathy. This study aimed to examine the therapeutic effect of formononetin in streptozotocin (STZ)-induced diabetic nephropathy through measuring biochemical parameters, oxidative indicators, and histopathological examination of renal tissues.

Results: Administration of a dose of STZ (55 mg/kg of body weight) intraperitoneal induced diabetic nephropathy in rats as indicated by an increase in serum glucose, creatinine, triglyceride, cholesterol, and BUN levels related to the depletion of serum albumin level. Besides, STZ treatment led to the depletion of antioxidant enzymes together with superoxide dismutase (SOD), glutathione (GSH), and catalase (CAT). Administration of formononetin at the dose of 10,20 , and $40 \mathrm{mg} / \mathrm{kg}$ extensively decreased biochemical parameters with a rise in serum albumin level. Formononetin was observed to improved antioxidant enzyme ranges and offered protection against lipid peroxidation (LPO). STZ administered rats show an elevated level of TNF-a and IL-6. Meanwhile, formononetintreated rats inhibited the elevated level of cytokine.

Conclusion: This study concluded that formononetin may additionally modulate oxidative stress and protected renal tissues from STZ injury. It also showed improvement in renal histopathological architecture in STZ-induced diabetic nephropathy.
\end{abstract}

Keywords: Diabetic nephropathy, Formononetin, Antioxidant activity, Oxidative stress

\section{Background}

Diabetic nephropathy (DN), also known as diabetic kidney disorder, is a major complication of long-standing diabetes mellitus. Nearly $40 \%$ of patients of diabetes expand DN because of continual hyperglycemia. Chronic hyperglycemia leads to progressive structural changes inside the renal tissues such as extracellular accumulation in the mesangium, glomerular basement membrane, and tubulointerstitial tissue [1]. DN is characterized by specific

\footnotetext{
* Correspondence: pgjain@yahoo.com

${ }^{1}$ Department of Pharmacology, R. C. Patel Institute of Pharmaceutical Education and Research, Dist-Dhule, Shirpur, Maharashtra 425405, India Full list of author information is available at the end of the article
}

renal morphological alterations consisting of glomerular sclerosis and tubular fibrosis leading to functional impairment inside the form of an upward push of urinary albumin excretion [2]. Persistently, high glucose level induces oxidative stress leading to the production of reactive oxygen species (ROS) which can be responsible for renal cellular injury. Current treatment modalities for diabetes primarily focus on glycemic and lipid control or lifestyle changes. These therapeutic approaches are insufficient to control oxidative stress and subsequent progression of $\mathrm{DN}$. Hence, there is an urgent need to explore the underlying mechanism and novel treatment for $\mathrm{DN}$.

\section{Springer Open}

(๑) The Author(s). 2020 Open Access This article is licensed under a Creative Commons Attribution 4.0 International License, which permits use, sharing, adaptation, distribution and reproduction in any medium or format, as long as you give appropriate credit to the original author(s) and the source, provide a link to the Creative Commons licence, and indicate if changes were made. The images or other third party material in this article are included in the article's Creative Commons licence, unless indicated otherwise in a credit line to the material. If material is not included in the article's Creative Commons licence and your intended use is not permitted by statutory regulation or exceeds the permitted use, you will need to obtain permission directly from the copyright holder. To view a copy of this licence, visit http://creativecommons.org/licenses/by/4.0/. 
Formononetin is a non-steroidal polyphenolic compound obtained from Astragalus membranaceus and Astragalus mongholicus root [3]. This phytochemical is known for its estrogenic activity due to its binding to the estrogen receptor (ER) and the induction of specific estrogen-responsive gene product. It is commonly found in legume plants including green peas, licorice roots, soybeans, flowering tops of red clover, astragalus roots [4], cauliflower, and iceberg lettuce [5]. Previous clinical study concluded the role of formononetin along with another isoflavone in the improvement of systemic arterial compliance [6]. Additionally, it was observed to be powerful in postmenopausal girls and obese men for a reduction in arterial stiffness and blood pressure [7]. Formononetin affords effective cardioprotection using inhibiting mitogenactivated protein (MAP) kinase activity [8]. It is called a potent activator of peroxisome proliferator-activated receptors (PPAR) alpha and gamma which modify glucose metabolism and dyslipidemi a[9]. In an experimental study, formononetin is known to enhance the antihyperglycemic effect of fangchinoline through growing insulin secretion from pancreatic beta cells in type 1 diabetic mice [10]. In vitro study demonstrated the defensive effect of formononetin by inhibiting pancreatic beta-cell apoptosis in diabetes mellitus. This effect was produced through the downregulation of nuclear factor-kappa B (NF-kB) and a decrease in the production of nitric oxide [11]. However, formononetin did not produce a hypoglycemic effect in streptozotocin-induced type 1 diabetes in C57BL/6 mice [12]. Therefore, the present study was undertaken to analyze the renoprotective effect of formononetin on STZ caused DN in rat version.

\section{Methods}

\section{Animals}

Thirty-six male Albino Wistar rats weighing 180-220 g were used for this experimental examination. Rats were procured from animal house facility of the R. C. Patel Institute of Pharmaceutical Education and Research, Shirpur, Dist-Dhule-Maharashtra). Animals were placed in nicely ventilated polypropylene cages and maintained under an ambient temperature of $25 \pm 2{ }^{\circ} \mathrm{C}, 12$-h light/ dark cycle in the departmental animal house. The animals had been fed with trendy pelletized feed (Amrut Rat Feed, Pune) and water ad libitum. The experimental protocol was pre-accepted by the institutional animal ethical committee (IAEC), protocol approval no. RCPI PER/IAEC/2018-19/06.

\section{Chemicals and drugs}

STZ, formononetin, metformin, and carboxymethylcellulose were obtained from Sigma Aldrich (Mumbai, India). Glucose kit, creatinine kit, urea/BUN kit, albumin kit, and total protein kit were received from ERBA (Mumbai,
India). Tumor necrosis factor-alpha (TNF- $\alpha$ ) and interleukin-6 (IL-6) were purchased from Loba Chemicals Pvt Ltd (Mumbai, India). All other chemicals used in the study were of analytical grade.

\section{Induction of diabetic nephropathy}

Diabetes was induced in rats by a single dose of STZ $(55 \mathrm{mg} / \mathrm{kg})$ intraperitoneal route except for the normal group. STZ was prepared in cold phosphate buffer solution (pH-7.4) in dark conditions. After $72 \mathrm{~h}$ of STZ administration, DN was induced in animals [13].

\section{Experimental design}

Rats were randomly divided into six groups $(n=6)$.

Group 1: Normal - received 0.5\% CMC

Group 2: Diabetic nephropathic group (DN) - injected with STZ $(55 \mathrm{mg} / \mathrm{kg})$

Group 3: DN + Standard drug (Metformin) - injected with STZ $(55 \mathrm{mg} / \mathrm{kg})+$ metformin $(70 \mathrm{mg} / \mathrm{kg})$

Group 4 to 6: Injected with STZ $(55 \mathrm{mg} / \mathrm{kg})$ and 10 , 20 , and $40 \mathrm{mg} / \mathrm{kg}$ of formononetin, respectively.

Metformin and formononetin suspension was prepared in $0.5 \% \mathrm{CMC}$ and administered by oral route for 14 days. On the 15th day, animals were anesthetized by urethane $(1.4 \mathrm{mg} / \mathrm{kg})$ [14] and blood samples were collected. For separation of the serum, the blood was centrifuged at $5000 \mathrm{rpm}$ for $10 \mathrm{~min}$ at $4{ }^{\circ} \mathrm{C}$ and the serum was separated and used for further biochemical estimation. Finally, animals were sacrificed and both kidneys were isolated. A $10 \%$ tissue homogenate of the kidney was prepared using ice-cold $50 \mathrm{mM}$ phosphate buffer saline ( $\mathrm{pH}$ 7.4). The homogenate was centrifuged at 10000 rpm for $10 \mathrm{~min}$ at $4{ }^{\circ} \mathrm{C}$, and the supernatant was separated and used for further estimation.

\section{Physiological parameters}

The body weight of each animal was recorded weekly by using an electronic weighing balance. At the end of the experiment, the weight of both kidney and liver was taken.

\section{Assessment of kidney function}

On the 14th day of study, rats were kept individually in metabolic cages for $24 \mathrm{~h}$ urine collection for the measurement of urine output and renal function. Before urine collection, blood samples were collected by retro-orbital puncture for separation of the serum. Renal function was assessed by measuring serum levels of fasting glucose by the glucose oxidaseperoxidase method, creatinine, and BUN, and blood albumin was measured using the commercially available marketed kit (Erba kit) [15]. 
Biochemical estimations in kidney homogenates

Renal oxidative stress biomarkers like GSH, SOD, and MDA were estimated using commercially available marketed kits according to the manufacturer's guidelines, and CAT was estimated using commercially available UV spectroscopic methods. Briefly, the kidney homogenate supernatant $(10 \mu \mathrm{L})$ was added to $0.5 \mathrm{~mL}$ of $10 \mathrm{mM}$ hydrogen peroxide $\left(\mathrm{H}_{2} \mathrm{O}_{2}\right)$ solution. The reduction in optical density of this mixture was measured at $240 \mathrm{~nm}$ by using a UV spectrophotometer. The rate of decrease in the optical density within $3 \mathrm{~min}$ from the addition of kidney homogenate was taken as an indicator of the catalase activity present in the homogenate [16].

\section{Cytokine parameters}

Proinflammatory cytokines like TNF- $\alpha$ and IL-6 were measured in kidney homogenate by using respective kits according to the manufacturer's protocol, and the final concentration was determined by using the standard curve [17].

\section{Histopathological examinations}

The kidney was removed from each rat by injecting a high dose of anesthesia (urethane $1.4 \mathrm{mg} / \mathrm{kg}$ i.p.) and buffered in formalin (10\%) solution and embedded in paraffin wax. The sample was then cut into around 5$\mu$ m-thick sections with a microtome and deparaffined with xylene. Then, sections were subjected to standard staining of hematoxylin/eosin. Sections were observed under a light microscope at magnifications of $\times 40$. Light microscopy was used to evaluate tubular necrosis and glomerular damage [18].

\section{Statistical analysis}

Data were presented as mean \pm S.E.M. of each group. The result values were statistically analyzed by using one-way ANOVA and two-way ANOVA followed by Bonferroni's test using graph pad prism version 7.0. A difference was regarded as significant when $P<0.05, P<$ 0.01 , and $P<0.001$.

\section{Results}

\section{Effect of STZ and formononetin on change in body and} organ weight

The bodyweight of the animals significantly decreased in STZ-treated group as compared to the normal group. Treatment with formononetin increased the body weight as compared to STZ-injected group $(P<0.001)$ shown in Fig. 1a, Whereas the metformin-treated group showed an increase in the body weight as compared to the STZ group $(P<0.001)$. Meanwhile, STZ-injected rats showed a decrease in kidney weight (Fig. 1b, c) and an increase in liver weight (Fig. 1d) as compared to normal rats. But the entire treatment group showed the reverse effect of STZ.
Effect of STZ and formononetin on urine output

Excretion of the urine was monitored at the end of the study for the evaluation of DN in the STZ-treated and drug-treated groups. Twenty-four hours of average urine volume was found to be $0.91 \mathrm{ml}$ in the control group. The STZ-treated group exhibited a significant rise in the average urine volume up to $4.1 \mathrm{ml}$. Metformin and formononetin treatment significantly inhibited such increased urine output as compared to STZ-treated group $(P<0.01)$ as showed in Fig. 2.

\section{Effect of formononetin on serum biochemical parameter} As shown in Fig. 3, STZ-treated rats showed marked impairment in renal functions as evident from the rise in the markers of glomerular and tubular damage like serum glucose, serum albumin, serum creatinine, BUN, serum cholesterol, and serum triglyceride activity as compared to the control group. Contrary, formononetin received group 3 showed a significant reduction in the serum level of BUN, glucose, albumin, and creatinine $(P<0.001)$.

\section{Effect of STZ and formononetin on oxidative stress in kidney tissue homogenate}

As shown in Fig. 4, lipid peroxidation was significantly high in STZ-treated rats as suggested by a marked increase in kidney MDA levels as compared to control rats $(P<0.001)$. Administration of different 3 doses of formononetin to the STZ-treated rats significantly restored the increased lipid peroxidation levels as compared to the STZ-treated rats $(P<0.001)$. STZ-treated groups showed a significant decrease in SOD and reduced GSH level and catalase activities $(P<0.001)$ in the kidney tissues. Metformin-treated rats show the similar effect like the normal rats. Administration of formononetin into the STZ-treated rats significantly increases the levels of $\mathrm{SOD}$, reduced $\mathrm{GSH}$, and kidney catalase activities as compared with STZ-treated rats $(P<0.001)$.

\section{Effect of STZ and formononetin on cytokine release}

The release of cytokine was measured by ELISA assay and showed a significant rise in TNF- $\alpha$ and IL- 6 in STZ-treated rats. This was indicated by a marked increase in kidney cytokine levels as compared to control rats $(P<0.001)$. Formononetin treatment at different doses in the STZ-treated rats significantly restored the increased cytokine levels as compared to the STZ-treated rats $(P<0.001)$ (Fig. 5).

\section{Effect of STZ and formononetin on histopathological examination}

Histopathological examination of the kidney section of the normal group showed healthy kidney tissue architecture. The section of the STZ-treated group exhibited similar features of the control group in addition to tubular necrosis with inflammatory cells. Blood vessels were 


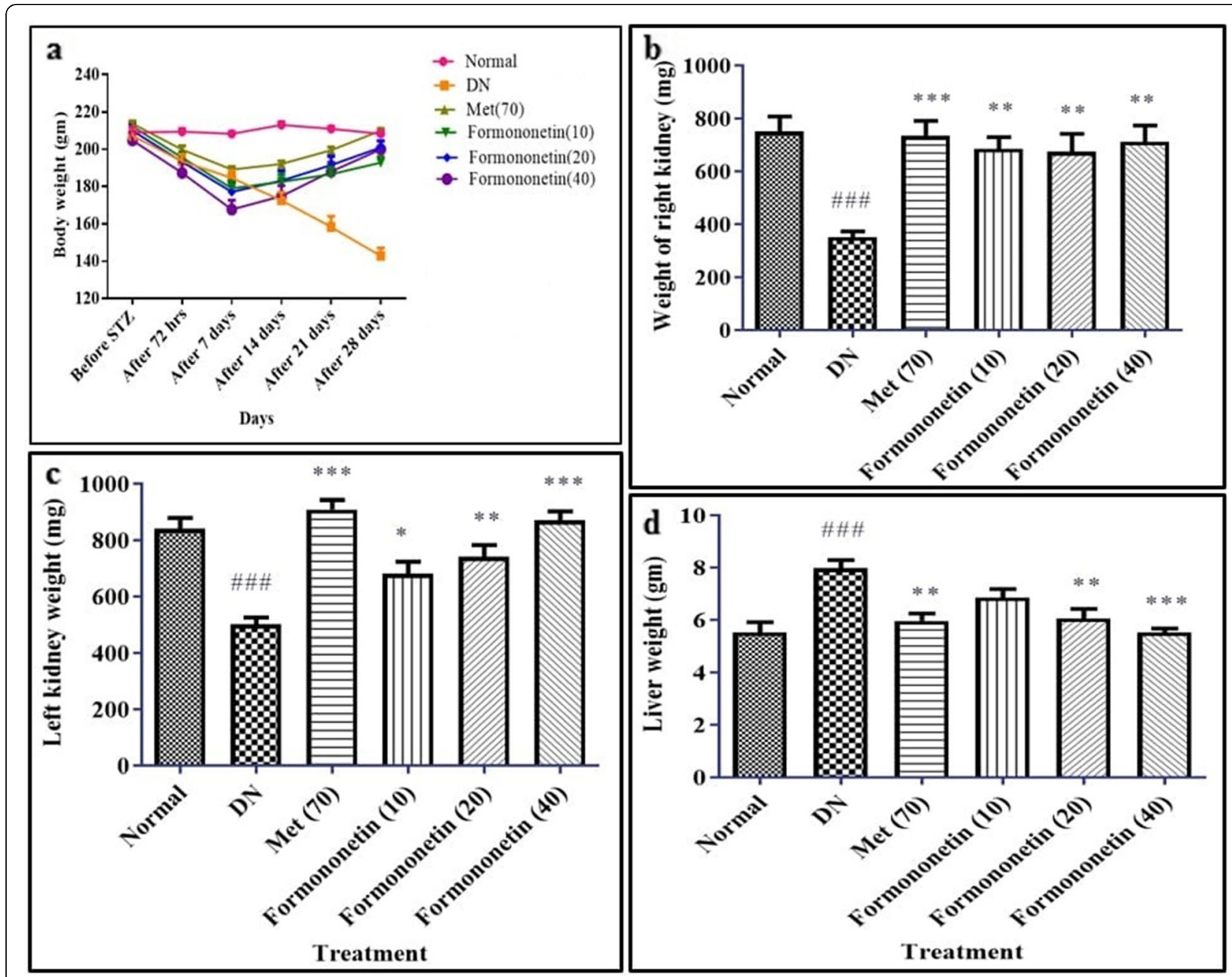

Fig. 1 Effect of formononetin on change in body and organ weight. Data were presented as mean \pm S.E.M. (n-6). The result values were statistically analyzed by using one-way ANOVA and two-way ANOVA followed by Bonferroni's test for multiple comparisons.

congested with interstitial edema. Cell damage was also observed in the STZ-treated group. STZ + metformin group showed comparatively least damage in the glomerulus. It can be observed that necrosis was also least compared to the STZ-treated group. However, formononetin treatment significantly reduced inflammatory changes and necrosis in renal cells. STZ-induced renal tissue damage attenuated by formononetin with an increase in its doses shown in Fig. 6.

\section{Discussion}

Oxidative stress and inflammation play a crucial role in the initiation and development of DN. Polyphenolic phytochemicals such as resveratrol, catechin, and genistein were proved for antidiabetic activities $[19,20]$. Isoflavone was a polyphenolic compound with a potent antioxidant effect. It was also recognized to enhance insulin secretion and improves glycemic management in diabetics $[15,21]$. Hyperlipidemia, oxidative pressure, and anti- inflammatory approaches were proposed inside the pathogenesis of type 2 diabetes [22]. Phytochemicals were known to act as a powerful antioxidant and halt the process of inflammation by controlling oxidative stress. Therefore, phytochemicals play a significant role in the control and management of diabetes mellitus and its complications. Previous research had stated the function of formononetin as a hypolipidemic, antiinflammatory, and antioxidant agent. It is far recognized to set off PPAR- $\alpha$ and PPAR- $\gamma$ receptors and inhibit the activation of the NF-kB pathway [23]. Additionally, formononetin exhibited an inhibitory effect on pancreatic $\beta$-cellular apoptosis and precipitated $\beta$-cellular regeneration [24].

In the present study, it was observed, Wistar rats were selected to induce pathological changes just like type 2 diabetes mellitus in humans. Streptozotocin was injected into rats to induce type 2 diabetes in the experimental model. As noted previously, the severity of $\beta$-cell 


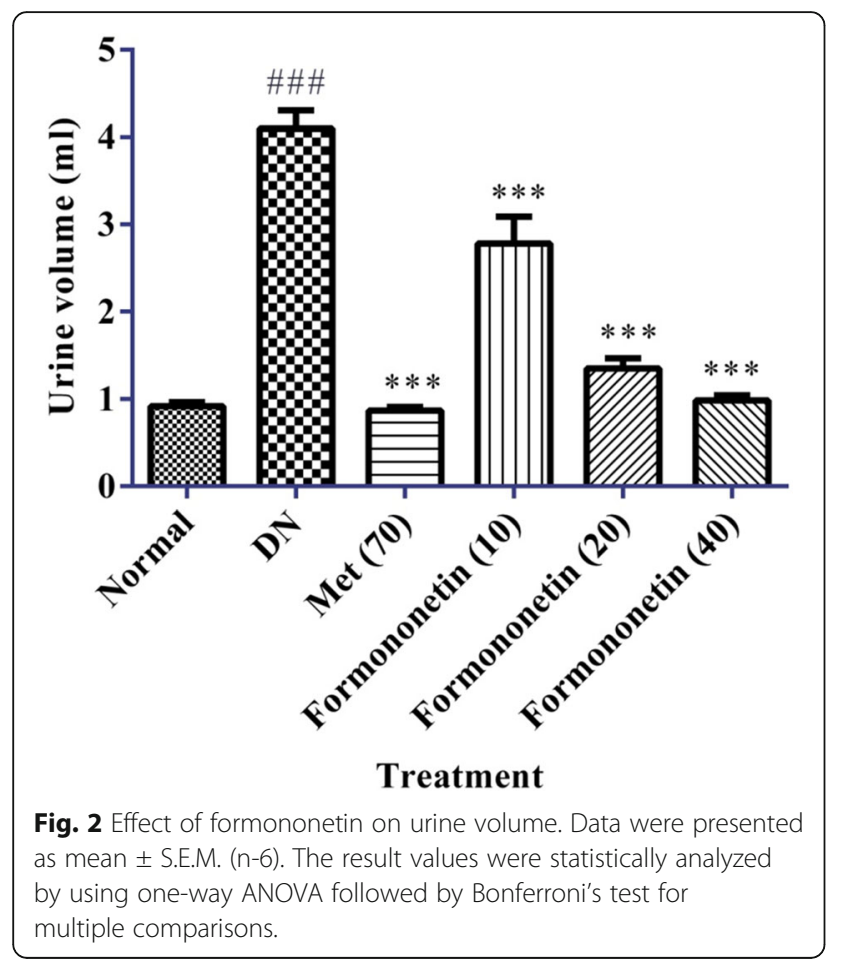

destruction depends on the dose of STZ treatment [10]. In order to produce type 2 diabetes, various authors recommended the STZ dose in the range of $25-55 \mathrm{mg} / \mathrm{kg}$ in rodent models. Hence, in the current study, STZ in a dose of $55 \mathrm{mg} / \mathrm{kg}$ was used to induce insulin resistance and partial $\beta$-cellular disorder [13].

The administration of STZ significantly reduces the weight of both kidneys in diabetic rats compared to normal rats. However, treatment with metformin and formononetin improved the weight of both kidneys. Similarly, the weight of the liver was increased in STZadministered groups and got reduced with the administration of metformin and formononetin. Results of the current study suggested that STZ in a dose of $55 \mathrm{mg} / \mathrm{kg}$ induced hyperglycemia and hyperinsulinemia in experimental animals. Treatment with formononetin produced better glycemic control which was equivalent to standard drug metformin. Results of the glucose test supported these findings. Formononetin at a dose of $40 \mathrm{mg} / \mathrm{kg}$ exhibited significant improvement in fasting glucose levels as compared to the diabetic control group. These data suggested that formononetin could produce an antidiabetic effect in diabetic rats.

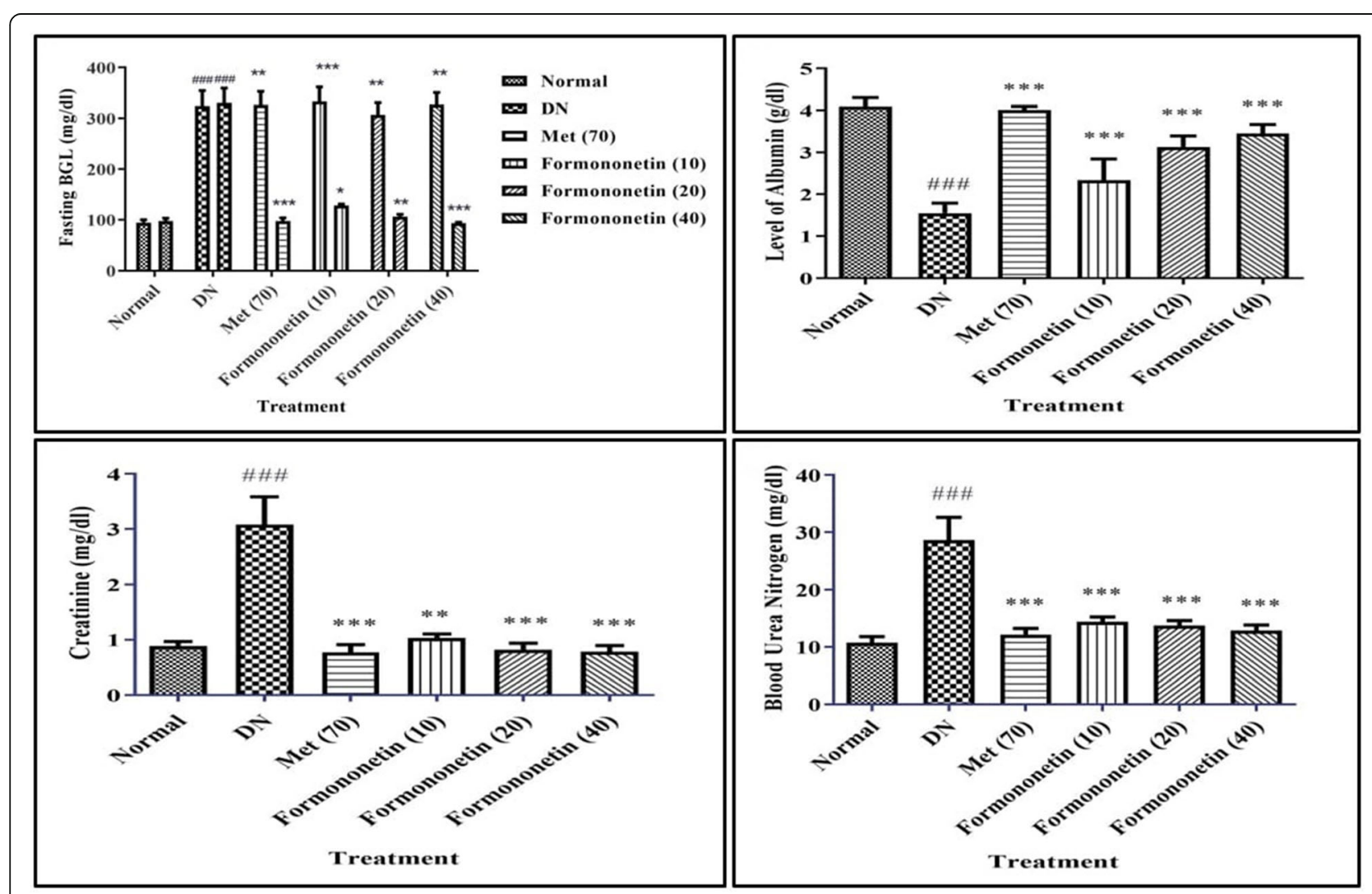

Fig. 3 Effect of formononetin on serum biochemical parameter. Data were presented as mean \pm S.E.M. (n-6). The result values were statistically analyzed by using one-way ANOVA and two-way ANOVA followed by Bonferroni's test for multiple comparisons. 


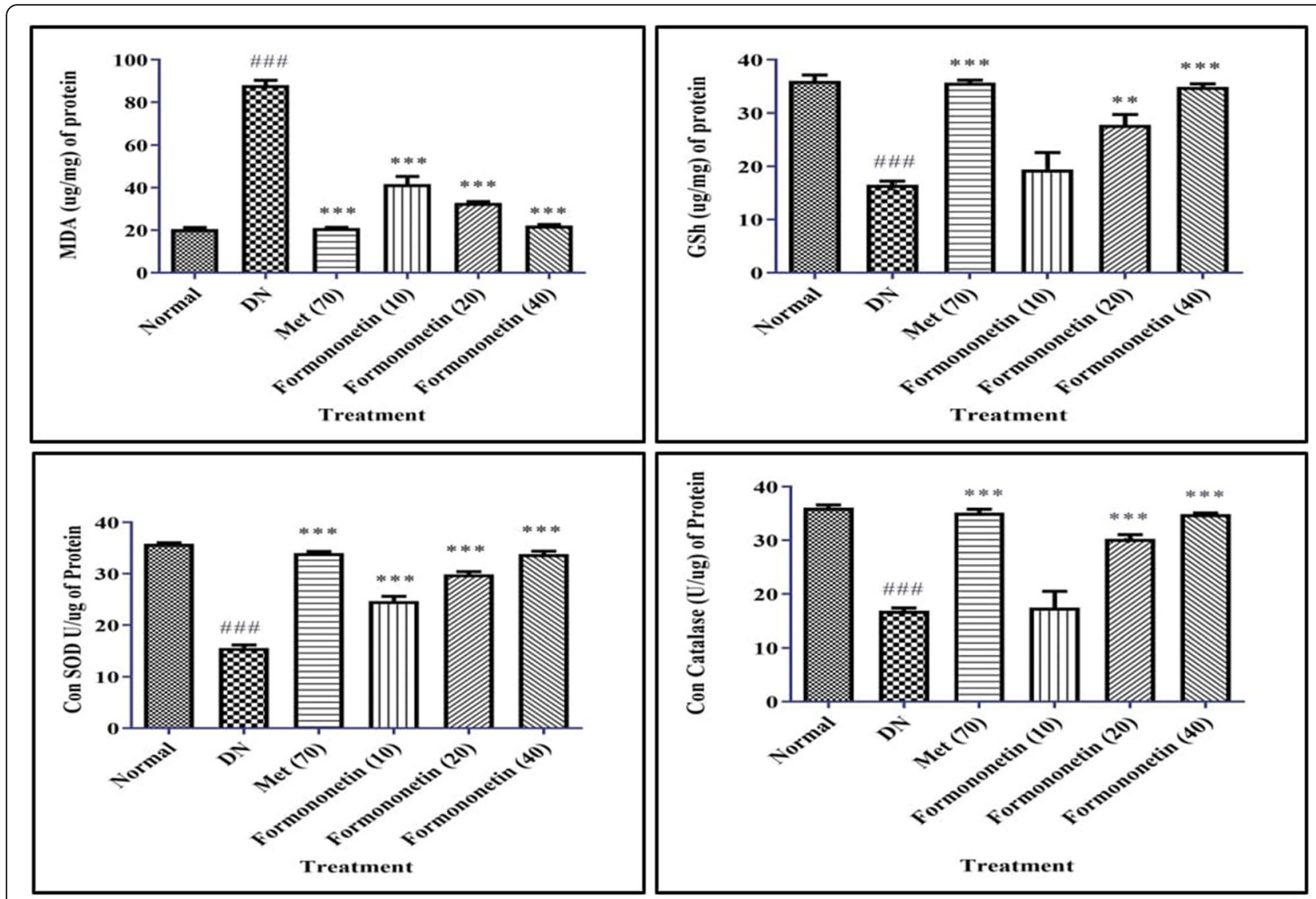

Fig. 4 Effect of STZ and formononetin on oxidative stress in kidney tissue homogenate. Data were presented as mean \pm S.E.M. (n-6). The result values were statistically analyzed by using one-way ANOVA followed by Bonferroni's test for multiple comparisons

Urinary albumin level was a selective marker of glomerular damage. Enhanced albumin excretion in experimental rats suggests modern nephropathy resulting in a loss of auto-regulation and inflammation. Several studies have mentioned that the reduction of microalbuminuria indicates a better prognosis in diabetic nephropathy [25]. Formononetin treatment efficiently reversed microalbuminuria equivalent to metformin remedy. This shows the role of formononetin in attenuating hyperfiltration and halting the progression of early diabetic nephropathy [13].

STZ treatment in diabetic rats leads to an increase in oxidative stress responsible for the development of diabetic complications [26]. The resemblance of pathological status in human diabetes with STZ caused hyperglycemia makes it a good model for the preliminary screening active agent against diabetes [27]. Continual hyperglycemias suppress the activity of antioxidant enzymes resulting in growth in the production of reactive oxygen species (ROS). ROS causes cellular damage leading to functional abnormalities in the organ. Cellular membranes and lipids were highly susceptible to the oxidative stress and peroxide reaction induced on by ROS [28]. Lipid peroxidation was traditionally an unfastened radical chain response initiated by the absorption of a hydrogen atom from a polyunsaturated fatty acid side chain. This process was initiated via ROS main to cellular damage by using the inactivation of membrane enzymes and receptors, depolymerization of polysaccharides, protein crosslinking, and fragmentation. Additionally, lipid peroxidation leads to the production of an extensive variety of cytotoxic merchandize which includes aldehydes. MDA is a main marker of endogenous lipid peroxidation [29]. In the current study, the activity of MDA was significantly increased in diabetic animals as compared to the normal group. However, treatment with formononetin significantly decreased MDA activity in a dose-dependent manner comparable to standard drug metformin. TNF- $\alpha$ and IL-6 were known as pro-inflammatory cytokines and are predictors of type 2 diabetes [30]. Both are thought to consider to mediate adverse metabolic effects resulting in insulin resistance and deteriorating glucose homeostasis [31]. The level of TNF- $\alpha$ and IL- 6 was significantly increased in STZ-induced diabetic animals as compared to 


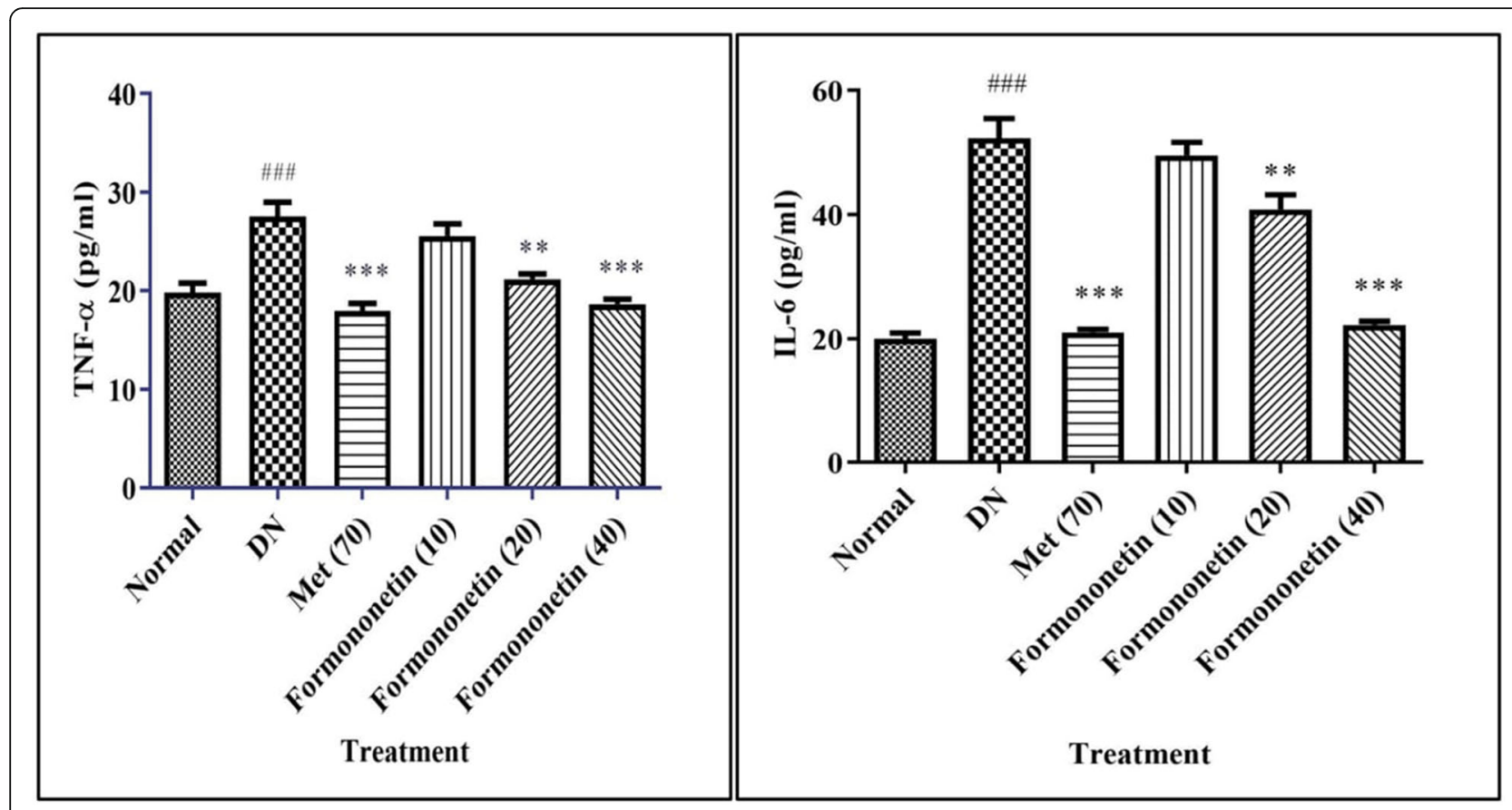

Fig. 5 Effect of STZ and formononetin on cytokine release. Data were presented as mean \pm S.E.M. (n-6). The result values were statistically analyzed by using one-way ANOVA followed by Bonferroni's test for multiple comparisons.
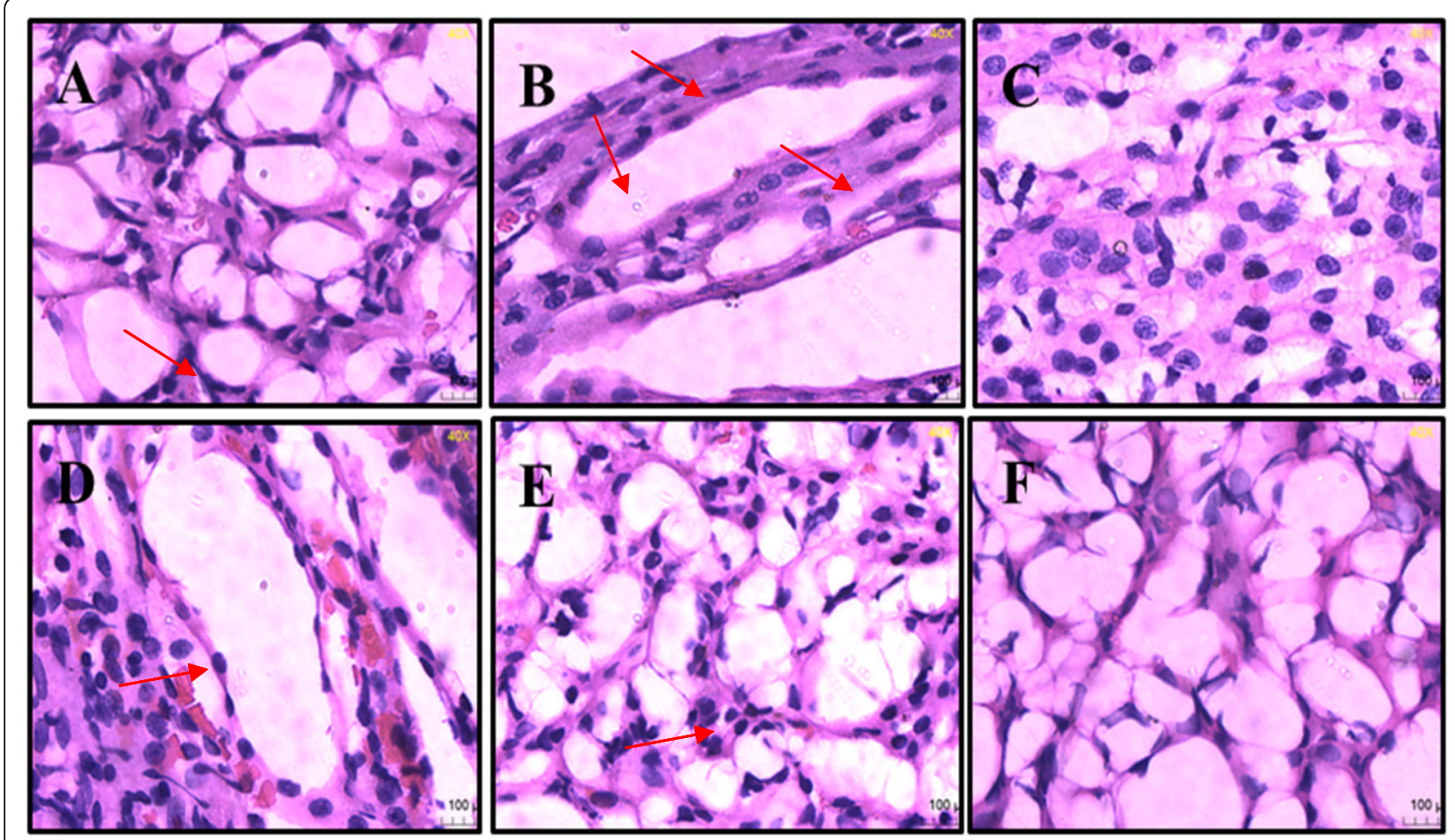

Fig. 6 Effect of STZ and formononetin on histopathological examination (sections were observed under a light microscope at magnifications of $\times 40$ ). a Normal, b DN, c Met (70), d formononetin (10), e formononetin (20), f formononetin (40) 
the normal group. Treatment with formononetin significantly decreased both and effect was equivalent to metformin.

On histopathological examination, the renal tissue of diabetic rats exhibited the presence of inflammatory, degenerative, necrotic, and hyperplastic lesions. Atrophy of renal tissue has also been observed in diabetic rats. Treatment with formononetin at the dose of $10 \mathrm{mg} / \mathrm{kg}$ showed little improvement in histological damage induced by diabetes. At the higher dose of 20 and $40 \mathrm{mg} /$ $\mathrm{kg}$ dose of formononetin, there were no signs of necrosis and atrophy of renal tissue. Taken together, the above results indicated that formononetin ameliorated diabetes-induced renal cell injury in DN rats.

\section{Conclusion}

Our study provides evidence for the renoprotective effect of formononetin in diabetes-induced renal injury. Antidiabetic activity elicited by formononetin might be due to its ability to activate antioxidant enzymes. The study results suggest that formononetin can be used in diabetic nephropathy and management of blood glucose, BUN, and serum creatinine. Further studies are needed to evaluate the therapeutic potential of formononetin in diabetic nephropathy in the human cell line model to find the mechanism.

\section{Acknowledgements}

Not applicable

\section{Authors' contributions}

PGJ designed all the experiments, analyzed data, and wrote the manuscript. PGN performed the experiments.

DJP-performed the experiments.

SDS analyzed data and wrote the manuscript.

SJS provided reagents and information.

The authors read and approved the final manuscript.

\section{Funding}

Not applicable

\section{Availability of data and materials}

All data and material are available upon request

\section{Ethics approval and consent to participate}

The experimental protocol was approved by the institutional animal ethical committee of R.C. Patel Institute of Pharmaceutical Education and Research Shirpur with protocol no. RCPIPER/IAEC/2018-19/06.

\section{Consent for publication}

Not applicable

\section{Competing interests}

The authors do not have conflicts of interest.

\section{Author details}

'Department of Pharmacology, R. C. Patel Institute of Pharmaceutical Education and Research, Dist-Dhule, Shirpur, Maharashtra 425405, India. ${ }^{2}$ Department of Pharmacology, Shri. R. D. Bhakt College of Pharmacy Jalna, Maharashtra 431203, India.
Received: 19 March 2020 Accepted: 6 August 2020

Published online: 12 August 2020

\section{References}

1. Gilbert RE et al (1998) Expression of transforming growth factor-beta1 and type IV collagen in the renal tubulointerstitium in experimental diabetes: effects of ACE inhibition. Diabetes 47(3):414-422. https://doi.org/10.2337/ diabetes.47.3.414

2. $\mathrm{Ha} \mathrm{H}$ and Lee HB (2000) Reactive oxygen species as glucose signaling molecules in mesangial cells cultured under high glucose. Kidney Interna 2000. 58: S19-S25. DOI: https://doi.org/10.1046/j.1523-1755.2000.07704.x

3. $\mathrm{Mu} \mathrm{H}$ et al (2009) Research on antioxidant effects and estrogenic effect of formononetin from Trifolium pratense (red clover). Phytomedi 16(4):314319. https://doi.org/10.1016/j.phymed.2008.07.005

4. Kaczmarczyk-Sedlak I et al (2013) Effect of formononetin on mechanical properties and chemical composition of bones in rats with ovariectomyinduced osteoporosis. Evid Based Complement Alternat Med:2013. https:// doi.org/10.1155/2013/457052

5. Kühnle A (2009) Self-assembly of organic molecules at metal surfaces. Curr Opin Colloid Interface Sci 14(2):157-168. https://doi.org/10.1016/j.cocis.2008. 01.001

6. Nestel PJ et al (1999) Isoflavones from red clover improve systemic arterial compliance but not plasma lipids in menopausal women. J Clinl Endocrinol Metabol 84(3):895-898. https://doi.org/10.1210/jcem.84.3.5561

7. Nestel P, Fujii A and L. Zhang (2007) An isoflavone metabolite reduces arterial stiffness and blood pressure in overweight men and postmenopausal women. Atherosclerosis, 192(1): 184-189. https://doi.org/10. 1016/j.atherosclerosis.2006.04.033

8. Dubey RK et al (1999) Phytoestrogens inhibit growth and MAP kinase activity in human aortic smooth muscle cells. Hypertension, 1999 33(1):177182. https://doi.org/10.1161/01.hyp.33.1.177

9. Alicic RZ, Rooney MT, Tuttle KR (2017) Diabetic kidney disease: challenges, progress, and possibilities. Clin J Ameri Socie Nephrol 12(12):2032-2045. https://doi.org/10.2215/CJN.11491116

10. Ma W et al (2007) Combined effects of fangchinoline from Stephania tetrandra Radix and formononetin and calycosin from Astragalus membranaceus Radix on hyperglycemia and hypoinsulinemia in streptozotocin-diabetic mice. Biol Pharmaceu Bulletin 30(11):2079-2083. https://doi.org/10.1248/bpb.30.2079

11. Wang $Y$ et al (2012) Formononetin attenuates $\mathrm{IL}-1 \beta$-induced apoptosis and NF-kB activation in INS-1 cells. Mol 2012. 17(9):10052-10064. https://doi.org/ 10.3390/molecules170910052

12. Qiu L et al (2012) Red clover extract ameliorates dyslipidemia in streptozotocin-induced diabetic C57BL/6 mice by activating hepatic PPARa. Phytother Res 26(6):860-864. https://doi.org/10.1002/ptr.3641

13. Somani R et al (2012) Asparagus racemosus Willd (Liliaceae) ameliorates early diabetic nephropathy in STZ induced diabetic rats. Indian J Exp Biol 50(7):469-475 http://nopr.niscair.res.in/handle/123456789/14328

14. Golder FJ, Robertson SA, Valverde A, Bolser DC (2003) Urethane anesthesia in adult female rats: preliminary observations. Vet Anaesth Analg 30(2):115115. https://doi.org/10.1046/j.1467-2995.2003.13335.x

15. Rufer CE, Kulling SE (2006) Antioxidant activity of isoflavones and their major metabolites using different in vitro assays. J Agric Food Chem 54(8): 2926-2931. https://doi.org/10.1021/jf0531120

16. Soon Y, Tan B (2002) Evaluation of the hypoglycemic and anti-oxidant activities of Morinda officinalis in streptozotocin-induced diabetic rats. Singapore Med J. 43(2):077-085

17. Jain PG et al (2018) Cardioprotective role of FA against isoproterenol induced cardiac toxicity. Mole Biol Reports 45(5):1357-1365. https://doi.org/ 10.1007/s11033-018-4297-2

18. Khairnar SI et al (2020) Disulfiram and its copper chelate attenuate cisplatininduced acute nephrotoxicity in rats via reduction of oxidative stress and inflammation. Biol Trace Elem Res 193(1):174-184. https://doi.org/10.1007/ s12011-019-01683-w

19. Tsuneki $\mathrm{H}$ et al (2004) Effect of green tea on blood glucose levels and serum proteomic patterns in diabetic $(\mathrm{db} / \mathrm{db})$ mice and on glucose metabolism in healthy humans. BMC Pharmacol 4(1):18-26. https://doi.org/ 10.1186/1471-2210-4-18

20. Cao $Z$ et al., (2007) Learning to rank: from pairwise approach to listwise approach. in Proceedings of the 24th international conference on Machine learning. 2007; 129-136. https://doi.org/10.1145/1273496.1273513 
21. Lu MP et al (2008) Dietary soy isoflavones increase insulin secretion and prevent the development of diabetic cataracts in streptozotocin-induced diabetic rats. Nutri Res 28(7):464-471. https://doi.org/10.1016/j.nutres.2008. 03.009

22. Rains JL, Jain SK (2011) Oxidative stress, insulin signaling, and diabetes. Free Radic Biol Med 50(5):567-575. https//doi.org/10.1016/ffreeradbiomed.2010.12.006

23. Medjakovic S, Mueller M, Jungbauer A (2010) Potential health-modulating effects of isoflavones and metabolites via activation of PPAR and AhR. Nutri 2(3):241-279. https://doi.org/10.3390/nu2030241

24. Qiu G et al (2017) Formononetin exhibits anti-hyperglycemic activity in alloxan-induced type 1 diabetic mice. Experi Biol Med 242(2):223-230. https://doi.org/10.1177/1535370216657445

25. Mogensen C (2003) Microalbuminuria and hypertension with focus on type 1 and type 2 diabetes. J Inter Med 254(1):45-66. https://doi.org/10.1046/j. 1365-2796.2003.01157.x

26. Johansen JS et al (2005) Oxidative stress and the use of antioxidants in diabetes: linking basic science to clinical practice. Cardiovascul Diabetol 4(1): 5-12. https://doi.org/10.1186/1475-2840-4-5

27. Srinivasan K, Ramarao P (2007) Animal model in type 2 diabetes research: an overview. Ind J Med Res 125(3):451-458

28. Blake $D$, Allen $R$, Lunec J (1987) Free radicals in biological systems-a review orientated to inflammatory processes. Br Med Bull 43(2):371-385. https://doi.org/10.1093/oxfordjournals.bmb.a072188

29. Oktem F, Ozguner F, Sulak O, Olgar S, Akturk O, Yilmaz HR, Altuntas I (2005) Lithium-induced renal toxicity in rats: protection by a novel antioxidant caffeic acid phenethyl ester. Mole Cellu Biochem 277(1-2):109-115. https:// doi.org/10.1007/s11010-005-5426-5

30. Mirza S, Hossain M, Mathews C, Martinez P, Pino P, Gay UL, Rentfro A, McCormick JB, Fisher-Hoch SP (2012) Type 2-diabetes is associated with elevated levels of TNF-alpha, IL-6 and adiponectin and low levels of leptin in a population of Mexican Americans: a cross-sectional study. Cyto 57(1): 136-142. https://doi.org/10.1016/j.cyto.2011.09.029

31. Moller DE (2000) Potential role of TNF-a in the pathogenesis of insulin resistance and type 2 diabetes. Trends Endrocrinol Metab 11(6):212-217. https://doi.org/10.1016/s1043-2760(00)00272-1

\section{Publisher's Note}

Springer Nature remains neutral with regard to jurisdictional claims in published maps and institutional affiliations.

\section{Submit your manuscript to a SpringerOpen ${ }^{\circ}$ journal and benefit from:}

- Convenient online submission

- Rigorous peer review

- Open access: articles freely available online

- High visibility within the field

- Retaining the copyright to your article

Submit your next manuscript at $\boldsymbol{\nabla}$ springeropen.com 